\title{
Double Patch Clamp Reveals That Transient Fusion (Kiss- and-Run) Is a Major Mechanism of Secretion in Calf Adrenal Chromaffin Cells: High Calcium Shifts the Mechanism from Kiss-and-Run to Complete Fusion
}

\author{
Abdeladim Elhamdani, Fouad Azizi, and Cristina R. Artalejo \\ Department of Pharmacology, Wayne State University School of Medicine, Detroit, Michigan 48201
}

\begin{abstract}
Transient fusion ("kiss-and-run") is accepted as a mode of transmitter release both in central neurons and neuroendocrine cells, but the prevalence of this mechanism compared with full fusion is still in doubt. Using a novel double patch-clamp method (whole cell/cell attached), permitting the recording of unitary capacitance events while stimulating under a variety of conditions including action potentials, we show that transient fusion is the predominant $(>90 \%)$ mode of secretion in calf adrenal chromaffin cells. Raising intracellular $\mathrm{Ca}^{2+}$ concentration $\left([\mathrm{Ca}]_{\mathrm{i}}\right.$ ) from 10 to $200 \mu \mathrm{m}$ increases the incidence of full fusion events at the expense of transient fusion. Blocking rapid endocytosis that normally terminates transient fusion events also promotes full fusion events. Thus, $[\mathrm{Ca}]_{\mathrm{i}}$ controls the transition between transient and full fusion, each of which is coupled to different modes of endocytosis.
\end{abstract}

Key words: exocytosis; endocytosis; kiss-and-run; fusion pore; membrane capacitance; chromaffin cell

\section{Introduction}

Since the development of the quantal hypothesis of transmitter secretion by Del Castillo and Katz (1954), it has been widely assumed that full vesicular fusion is the principal mechanism of exocytosis at central synapses. Recovery of vesicular components for recycling is postulated to occur through a clathrin-coated vesicle-based pathway (Heuser and Reese, 1973; De Camilli et al., 2000; Murthy and De Camilli, 2003; Dickman et al., 2005). Although this is still the prevailing dogma, an accelerating stream of evidence supporting alternative transient fusion mechanisms in neurons and neuroendocrine cells has emerged. Transient fusion (often known as "kiss-and-run") is envisaged to occur via a fusion pore between the vesicle and the surface membrane (Neher and Marty, 1982; Fernandez et al., 1984; Alvarez de Toledo et al., 1993). Transmitter or hormone can escape, often incompletely, through this aqueous channel between the vesicle interior and the extracellular space (Elhamdani et al., 2001; Aravanis et al., 2003; Taraska et al., 2003; Pawlu et al., 2004; Staal et al., 2004). The molecular nature of the fusion pore is still in doubt, although proteinaceous models involving SNARE (soluble $\mathrm{N}$ ethylmaleimide-sensitive factor attachment protein receptor) proteins have been proposed recently (Han et al., 2004). Because both transient and full fusion evidently occur in most secretory

Received Dec. 9, 2005; revised Feb. 1, 2006; accepted Feb. 4, 2006

This work was supported by National Institutes of Health Grants MH-47181 and DK-58921 (C.R.A.). We thank Dr. Clive H. Palfrey for very helpful comments on this manuscript.

Correspondence should be addressed to Dr. Abdeladim Elhamdani, Department of Pharmacology, Wayne State University, 540 East Canfield Avenue, Detroit, MI 48201. E-mail: aelhamda@med.wayne.edu.

D01:10.1523/JNEUROSCI.5275-05.2006

Copyright $\odot 2006$ Society for Neuroscience $\quad$ 0270-6474/06/263030-07\$15.00/0 cell types, a central question has been the relative preponderance of these alternate mechanisms, their relationship to stimulation conditions and indeed to each other, as well as the endocytotic mechanisms that terminate each process. In adrenal chromaffin (AC) cells that secrete the transmitter epinephrine from densecore vesicles (DCVs), we have proposed that different endocytotic processes are evoked by distinct patterns of stimulation. Rapid endocytosis (RE), a non-clathrin-dependent event, occurs with mild stimulation (Artalejo et al., 1995, 1996, 2002), whereas stronger and sustained levels of stimulation trigger a clathrindependent slow endocytosis (SE) (Artalejo et al., 2002). We hypothesized that RE is the terminal step of transient fusion, whereas SE is activated after full fusion events in these cells (Palfrey and Artalejo, 1998; Elhamdani et al., 2001). Here, we use a double patch-clamp approach to assess at the unitary event level transient versus full fusion in AC cells and their relationship to the two modes of endocytosis. We show that transient fusion is the major mechanism of secretion and that RE is intimately associated with this process. Full fusion events increase at levels of stimulation that generate high intracellular $\mathrm{Ca}^{2+}$ concentration $\left([\mathrm{Ca}]_{\mathrm{i}}\right)$ or when RE is abrogated by ion substitution.

\section{Materials and Methods}

Cell culture

Bovine calf (average age, 10-12 weeks) AC cells were prepared by collagenase digestion of adrenal medulla obtained from a local slaughterhouse. Cells were purified and cultured using previously described methods (Artalejo et al., 1995). AC cells, plated at a density of $3 \times 10^{5}$ cells on collagen-coated $35 \mathrm{~mm}$ diameter dishes, were used in all studies within 1 week of plating. 


\section{Electrophysiology}

Cell-attached capacitance measurements. Sine-wave stimuli were generated from a lock-in amplifier (SR830 DSP; Stanford Research Systems, Stanford, CA); the signal-to-noise ratio was optimized using a sine wave of $50 \mathrm{mV}$ amplitude and $20 \mathrm{kHz}$ frequency (Debus and Lindau, 2000). The current evoked at the patch was filtered at $10 \mathrm{kHz}$ and driven back from an EPC-10/2 (HEKA Elektronik, Lambrecht, Germany) to the lock-in amplifier input. The in-phase (real) and $90^{\circ}$ out-of-phase (imaginary) outputs of the lock-in amplifier, corresponding to the conductance and capacitance of the patch, respectively, were digitized using a Digidata BNC-2090 (National Instruments, Austin, TX) and stored at a 1 $\mathrm{kHz}$ sampling rate in a personal computer. The output filter of the lock-in amplifier was set to a time constant of $1 \mathrm{~ms}, 12 \mathrm{~dB}$. Data were acquired and analyzed using Igor (WaveMetrics, Lake Oswego, OR), and macros were developed in Dr. M. Lindau's laboratory (Cornell University, Ithaca, NY).

In cell-attached capacitance measurements, two parameters were monitored carefully. First, the formation of an $\Omega$ shape of the membrane inside the cell-attached pipette was avoided by applying minimum suction to obtain the seal between a freshly polished pipette and a clean cell membrane. Also, true changes of capacitance and conductance were assured by setting the correct phase and monitoring the effect of ion channel activity on the conductance trace. Two manipulations that affect the phase in a characteristic manner were used in setting the phase: a $100 \mathrm{fF}$ jump of the fast capacitance $\left(C_{\text {fast }}\right)$ and a slight suction force on the patch applied by mouth. Both should increase the capacitance without affecting the conductance of the patch, and they proved to be ideal tools for phase adjustment. To preclude ion channel activity effects on the conductance trace, patch current was recorded in parallel with real and imaginary traces.

For transient fusion events, vesicle capacitance $\left(C_{\mathrm{v}}\right)$ and fusion-pore conductance $\left(G_{\mathrm{p}}\right)$ were calculated from the imaginary (Im) and real (Re) traces corresponding to the admittance of the patch. $C_{\mathrm{v}}=\left[\left(\operatorname{Re}^{2}+\right.\right.$ $\left.\left.\mathrm{Im}^{2}\right) / \mathrm{Im}\right] / \omega$ and $G_{\mathrm{p}}=\left(\operatorname{Re}^{2}+\mathrm{Im}^{2}\right) /$ Re. For full fusion events, $C_{\mathrm{v}}=$ $\mathrm{Im} / \omega$, where $\omega$ is the angular frequency $(\omega=2 \pi f ; f$ is the sine-wave frequency). Occasionally, the fusion pore expanded slowly for a short period of time before full fusion. In this case, the conductance of the fusion pore was calculated from the Im trace only: $G_{\mathrm{p}}=\mathrm{Im} /(\mathrm{Im} /(\mathrm{Im}-$ 1) $)^{\wedge}$ [see Dernick et al. (2003) for a full description].

Pipettes were constructed of thin-wall borosilicate patch pipette glass. The resistance of the pipette was $\leq 1 \mathrm{M} \Omega$, and resistance of the seal was $\geq 20 \mathrm{G} \Omega$. The bath solution consisted of (in $\mathrm{mm}$ ) $140 \mathrm{NaCl}, 10$ glucose, 10 HEPES, $1 \mathrm{MgCl}_{2}, 5 \mathrm{KCl}$, and $5 \mathrm{CaCl}_{2}$, pH adjusted to 7.3 with $\mathrm{NaOH}$. The cell-attached pipette solution is the same as the bath solution. When 10 $\mathrm{mm} \mathrm{Sr}^{2+}$ or $\mathrm{Ba}^{2+}$ was substituted for $5 \mathrm{~mm} \mathrm{Ca}^{2+}, \mathrm{NaCl}$ was reduced to 130 mm. 1,1-Dimethyl-4-phenylpiperazinium iodide (DMPP) (final concentration, $10 \mu \mathrm{M}$ ) was added daily to the pipette solution from a fresh $10 \mathrm{~mm}$ stock solution. For cell-attached capacitance experiments with DMPP, the tip of the cell-attached pipette was dipped for $\sim 3 \mathrm{~s}$ in a DMPP-free pipette solution. Thereafter, the pipette was back filled with the same solution containing DMPP. The seal is made relatively fast, which reduces significantly the chance of the cell being exposed to DMPP from the pipette before the seal is secured.

Whole-cell capacitance measurements. For the double patch-clamp approach, we used an EPC-10/2 amplifier to simultaneously perform cellattached and whole-cell recordings. Whole-cell membrane capacitance was evoked by a $50 \mathrm{mV}$ (root mean square) sine wave at $1500 \mathrm{~Hz}$ using the manufacturer's Pulse software (HEKA Electronik). RE was evoked with a brief stimulation protocol $(10 \times 50 \mathrm{~ms})$ pulse at $2 \mathrm{~Hz}$, and SE was evoked with a sustained stimulation protocol $(29 \times 75 \mathrm{~ms})$ pulse at $0.25 \mathrm{~Hz}$. Each stimulation pulse corresponds to a depolarization of the cell from a holding potential of -80 to $+10 \mathrm{mV}$, which is preceded by a $50 \mathrm{~ms}$ prepulse to $+120 \mathrm{mV}$ to recruit the facilitation $\mathrm{Ca}^{2+}$ channels (Artalejo et al., 2002). The patch pipette contained (in mM) $100 \mathrm{~K}$-glutamate, $12 \mathrm{NaCl}$, 30 HEPES, $5 \mathrm{MgCl}_{2}$, 2 ATP, 0.35 GTP, and 0.1 EGTA, pH adjusted to 7.2 with $\mathrm{KOH}$. To fix the $[\mathrm{Ca}]_{\mathrm{i}}$ at different levels, we used the same composition of this solution, except that EGTA was replaced by a ratio of Ca-chelator/total $\mathrm{CaCl}_{2}\left[2.5 / 0.5 \mathrm{~mm}\right.$ for $10 \mu \mathrm{M}$ free $\mathrm{Ca}^{2+}$ using $N-(2-$ hydroxyethyl)ethylenediaminetriacetate $\left(K_{\mathrm{d}}=4.86 \mu \mathrm{M}\right) ; 1.8 / 0.66 \mathrm{~mm}$ for $102 \mu \mathrm{M}$ using nitrolo-triacetic acid (NTA) $\left.\left(K_{\mathrm{d}}=136 \mu \mathrm{M}\right)\right]$ and a ratio of 1.1/0.73 mM for $210 \mu \mathrm{M}$ free $\mathrm{Ca}^{2+}$ using NTA. For maximal buffering capacity, the range of free $\mathrm{Ca}^{2+}$ was $>K_{\mathrm{d}} / 3.2$ and $<K_{\mathrm{d}} \times 3.2$. The MaxChelator program (Stanford University, Stanford, CA) was used for this purpose. To block RE with $\mathrm{Sr}^{2+}$ or $\mathrm{Ba}^{2+}$ as charge carrier, bath $\mathrm{Ca}^{2+}$ was replaced on an equimolar basis.

\section{Current-clamp recording}

To evoke action potentials (APs) while recording cell-attached capacitance, the cells were stimulated by $10 \mathrm{~ms}$ depolarizing currents $(20-40$ $\mathrm{pA})$; the resting potential of the cells was approximately $-80 \mathrm{mV}$ that was maintained through application of a holding current of 0 or $-1 \mathrm{pA}$ (Elhamdani et al., 2001). The pipette solution contained (in $\mathrm{mM}$ ) 100 K-glutamate, $0.1 \mathrm{~K}$-EGTA, $12 \mathrm{NaCl}, 30 \mathrm{HEPES}, 5 \mathrm{MgCl}_{2}$, 2 ATP, 0.35 GTP, pH 7.2 adjusted with $\mathrm{KOH}$. The external solution consisted of (in mm) $140 \mathrm{NaCl}, 10$ glucose, $10 \mathrm{HEPES}, 1 \mathrm{MgCl}_{2}, 4 \mathrm{KCl}$, and $5 \mathrm{CaCl}_{2}, \mathrm{pH}$ 7.3 adjusted with $\mathrm{NaOH}$. All experiments were performed at room temperature $\left(24^{\circ} \mathrm{C}\right)$. Data are mean $\pm \mathrm{SEM}$. Statistical significance was evaluated using the Peritz test.

\section{Results}

Previously, we used whole-cell capacitance measurements in calf AC cells to assess global exocytosis and endocytosis events as well as amperometry to detect the kinetics of unitary fusion events (Artalejo et al., 1995, 1996, 2002; Elhamdani et al., 1998, 1999, 2001). Here, we have improved this procedure to double patchclamp cells to precisely control the intracellular milieu with a whole-cell pipette while simultaneously recording unitary capacitance events in the cell-attached configuration. In the latter procedure, noise is sufficiently low that fusion of single DCVs can be resolved readily. To determine the efficacy of cell-attached recordings in the present setup, we first stimulated cells with the nicotinic agonist DMPP $(10 \mu \mathrm{M})$ using a single cell-attached electrode. As shown in Figure 1, individual fusion events were clearly resolved. It was immediately apparent that the majority of the events represented transient fusion. In fact, from a total of 29 cells in which at least one secretory event was recorded, 169 transient fusion events, but only 18 full fusion events, were obtained. That each transient event is derived from a single vesicle fusion is predicated on the observation that the coefficient of correlation between the up and subsequent down step is close to 1 (data not shown). Full fusion was classified as a jump in the capacitance trace that did not return to baseline during the course of the recording, accompanied by no change or a brief transient in the resistance trace. Three parameters are used to describe the characteristics of the transient events: vesicle capacitance $\left(C_{\mathrm{v}}\right)$, fusion pore conductance $\left(G_{\mathrm{p}}\right)$, and the event duration. $C_{\mathrm{v}}$ and $G_{\mathrm{p}}$ were calculated from the imaginary $(\mathrm{Im})$ and real (Re) traces (Fig. 1B) using equations described in Materials and Methods, and the distributions of these parameters for transient fusion events are shown in Figure $1 C$. The average $C_{\mathrm{v}}$ was $2.1 \pm 0.04 \mathrm{fF}$ (range, $1-3.5 \mathrm{fF}$ ), close to the estimated average for a single DCV in AC cells (Neher and Marty, 1982). Assuming a membrane capacitance value of $9 \mathrm{fF} / \mu \mathrm{m}^{2}$, the mean vesicle radius was $130 \pm 1.3$ $\mathrm{nm}$, also in line with previous microscopic determinations of this parameter in AC cells stimulated with nicotine (Ornberg et al., 1995). These results support the idea that we are examining fusion of single vesicles with the surface membrane in the cellattached recordings. The mean $G_{\mathrm{p}}$ was $250 \pm 5.4 \mathrm{pS}$ (range, $70-$ $500 \mathrm{pS}$ ), which is slightly lower than the values reported for DCVs in posterior pituitary cells $[\sim 300 \mathrm{pS}$ (Klyachko and Jackson, 2002)] and adult bovine AC cells [ $\sim 330$ or $\sim 400$ pS (Alés et al., 1999; Dernick et al., 2003)]. A histogram distribution of unitary event duration exhibits a mean value of $223 \pm 15 \mathrm{~ms}$ (range, 26-962 ms). In this study, we did not separate between burst of events from the same or different vesicles. Henkel et al. (2000) 
defined a burst from the same vesicle as at least three events occurring in $<3$ s. However, as shown in Figure $3 \mathrm{Bb}_{3}$, four successive events from at least two different granules (two transients and two full fusion events) did occur in $<1 \mathrm{~s}$.

Full fusion events had a similar size $\left(C_{\mathrm{v}}=1.98 \pm 0.17 \mathrm{fF} ; n=18\right)$ to transient fusion events (data not shown), but before merging completely with the plasma membrane, some vesicles ( 8 of 18 ) formed a significantly larger fusion pore $\left(G_{\mathrm{p}}=\right.$ $358 \pm 50 \mathrm{pS})$ that stabilizes for a few milliseconds before full expansion.

\section{APs trigger predominantly transient fusion events}

Having established the ability of the cellattached pipette to monitor single fusion events in calf AC cells, we then turned to a double patch-clamp approach in which the second whole-cell electrode is used to stimulate the cell with APs and control $[\mathrm{Ca}]_{\mathrm{i}}$ in a precise manner via intracellular buffer infusion (Fig. 2A). In this configuration, we found that APs at 1 or $7 \mathrm{~Hz}$ trigger single exocytotic events almost entirely by a transient fusion mechanism (Fig. 2B). APs at $1 \mathrm{~Hz}$ triggered 69 transient fusion events gathered from 15 cells, with no full fusion events that were apparent at this frequency. APs at $7 \mathrm{~Hz}$ triggered more full fusion events ( $n=14)$, but transient fusion still predominated ( $n=150$ in 19 cells). Cumulative data from transient fusion events are shown in Figure $2 C$ as histograms. The mean values of $C_{\mathrm{v}}$ are statistically indistinguishable in each case, but APs at $7 \mathrm{~Hz}$ slightly increased the mean value of $G_{\mathrm{p}}$ from $159 \pm 4.3$ to $179 \pm$ $5.1 \mathrm{pS}(p<0.02)$ and reduced the mean unitary event duration significantly from $195 \pm 28$ to $82 \pm 6 \mathrm{~ms}(p<0.001)$. Previously, amperometry data in AC cells showed that the duration of the entire amperometric spike was shortened, and the total charge (amount of catecholamine released per spike) was significantly elevated when AP frequency was raised from 1 to 7 $\mathrm{Hz}$ (Elhamdani et al., 2001) or $0.5-15 \mathrm{~Hz}$ (Fulop et al., 2005). Furthermore, Fulop et al. (2005) showed that bigger fluorescent molecules ( 7 and $12 \mathrm{~nm}$ diameter) could be uptaken into the cell via a bigger fusion pore opening at $15 \mathrm{~Hz}$ but not $0.5 \mathrm{~Hz}$. Together with the present results, this suggested the possibility that higher $[\mathrm{Ca}]_{\mathrm{i}}$, consequent after an increase in stimulation frequency, increases the fusion pore conductance and speeds up its closure, as well as promotes full fusion events. To test these hypotheses, we stimulated cells in the presence of different levels of free $[\mathrm{Ca}]_{\mathrm{i}}$ clamped with buffers.

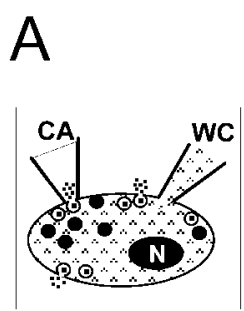

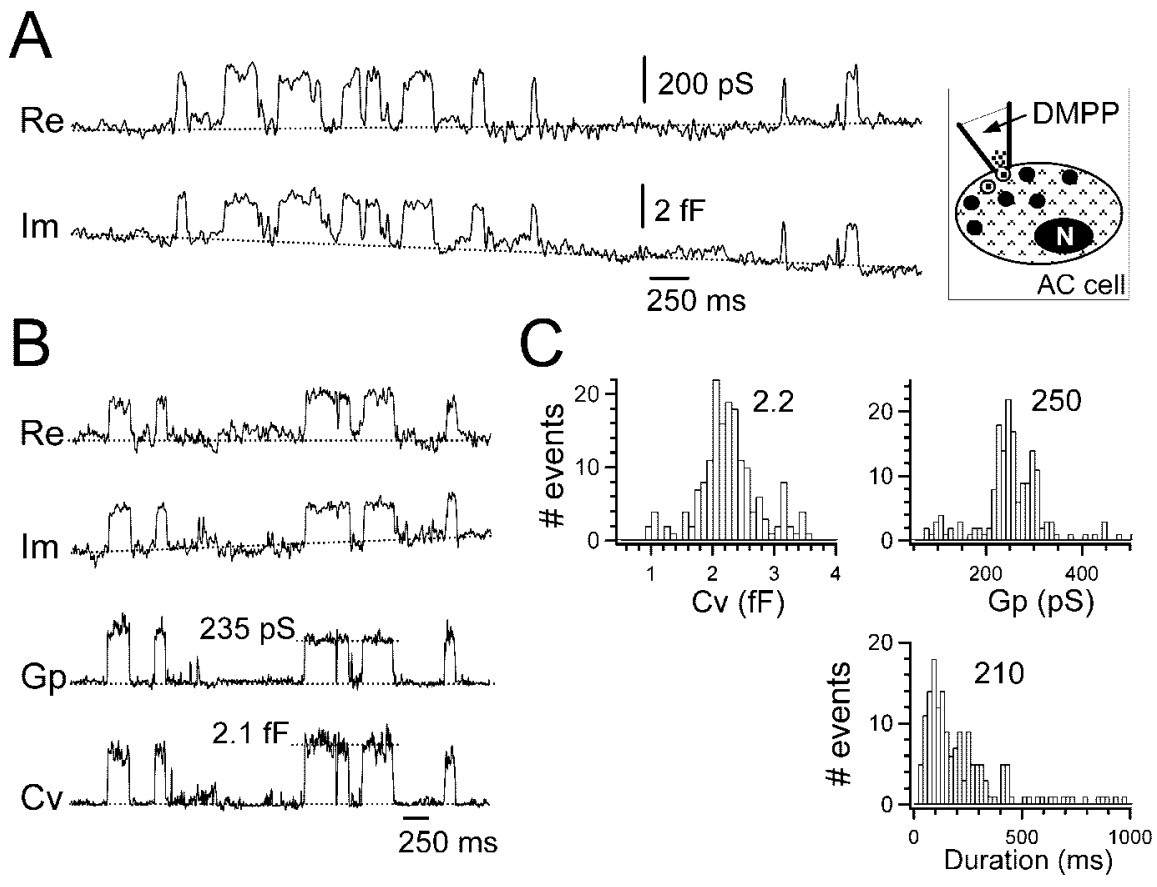

Figure 1. DMPP triggers burst and isolated single secretory events. $\boldsymbol{A}$, Real and imaginary traces, evoked by $10 \mu \mathrm{M}$ DMPP, correspond, respectively, to the conductance and capacitance of the patch under a cell-attached pipette, as shown in the inset. N, Nucleus. $\boldsymbol{B}$, Fusion pore conductance $\left(G_{\mathrm{p}}\right)$ and vesicle capacitance $\left(C_{\mathrm{v}}\right)$ of transient fusion events are calculated from real and imaginary traces as follows: $G_{p}=\left(\operatorname{Re}^{2}+\operatorname{Im}^{2}\right) / R e ; C_{v}=\left[\left(\operatorname{Re}^{2}+\mathrm{Im}^{2}\right) / \mathrm{Im}\right] / \omega$ (see Materials and Methods). $C$, Histogram of the $C_{v}, G_{p}$, and event duration ( $n=169 ; 18$ cells) with their corresponding mean values. When DMPP was omitted from the pipette solution, from 141 cells tested, only 6 cells had a total of three transient fusion events and seven full fusion events (data not shown), indicating that cells were primarily quiescent before stimulation. DMPP triggered the first event with a mean delay time of $167 \pm 28 \mathrm{~s}$ (see Materials and Methods). Increasing DMPP to $100 \mu \mathrm{m}$ did not decrease the delay time or increase the number of events. Re, Real; Im, imaginary.

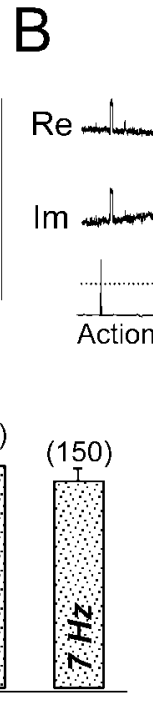

$1 \mathrm{~Hz}$

$7 \mathrm{~Hz}$
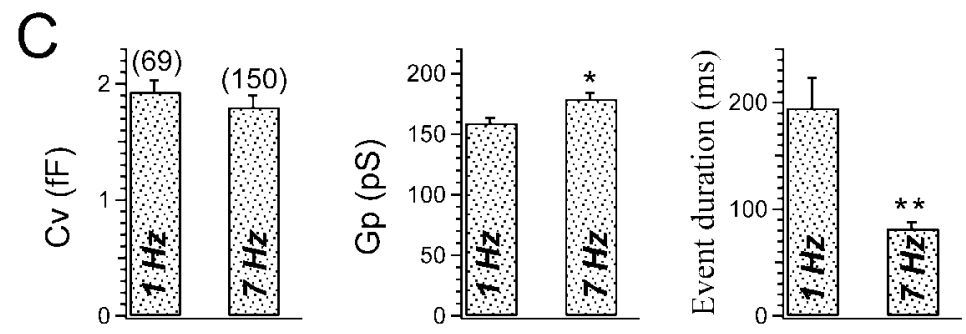

Figure 2. APs trigger predominantly transient fusion events. $\boldsymbol{A}$, Diagram showing the double patch-clamp approach: the left patch pipette in the cell-attached configuration (CA) to record capacitance and conductance of single secretory events and the right pipette in the whole-cell configuration (WC) to stimulate the cell with APs. N, Nucleus. B, Conductance (Re) and capacitance (Im) traces show transient fusion events evoked by APs shown underneath at 1 and $7 \mathrm{~Hz}$. $C$, Histograms of the mean values of the $C_{v^{\prime}} G_{p^{\prime}}$ and event duration of the transient events evoked by APs at $1 \mathrm{~Hz}$ ( 69 events, 15 cells) and $7 \mathrm{~Hz}$ (150 events, 19 cells). Each cell was stimulated with different rounds of 150 or $500 \mathrm{APs}$, separated by a 4 min resting period, at 1 or $7 \mathrm{~Hz}$, respectively.

Different levels of free $[\mathrm{Ca}]_{\mathrm{i}}$ dictates the fate of fusing vesicles Different levels of free $[\mathrm{Ca}]_{i}$ were delivered to the cell interior through the whole-cell pipette, and exocytosis was monitored by concurrently recording both whole-cell and cell-attached capac- 


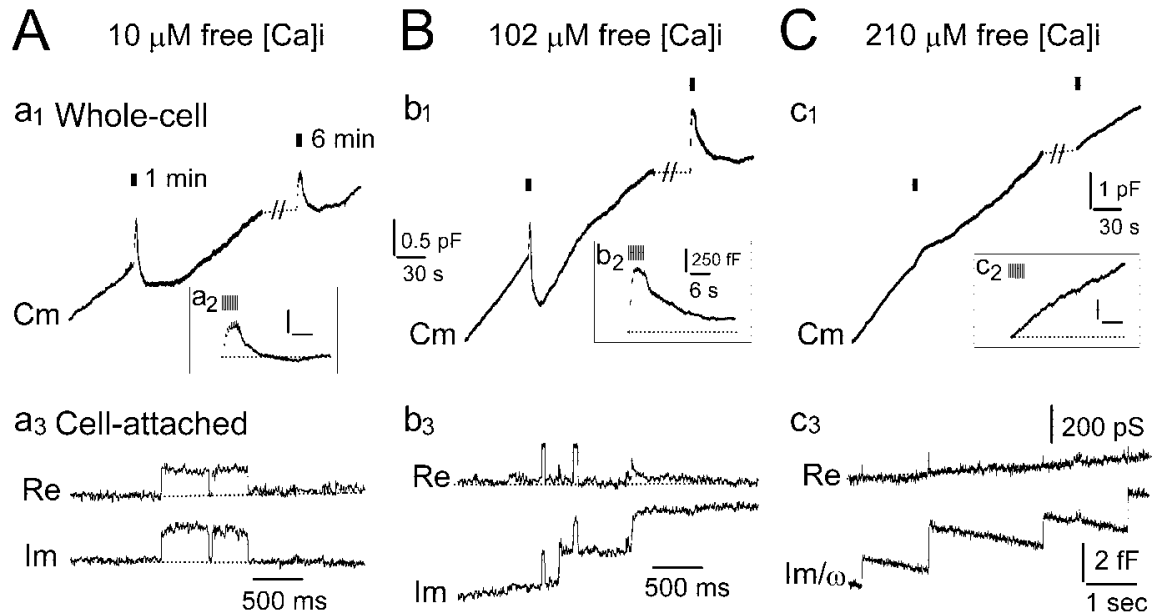

Figure 3. High $[\mathrm{Ca}]_{\mathrm{i}}$ switches the mode of fusion from transient to full. $\boldsymbol{A}, \mathrm{A}$ concentration of $10 \mu \mathrm{m}$ free $[\mathrm{Ca}]_{\mathrm{i}}$, dialyzed into the cell through the whole-cell patch pipette, induces a continuous increase in the whole-cell membrane capacitance $\left(C_{m}\right)\left(\boldsymbol{a}_{\boldsymbol{\gamma}}\right)$ at a rate of $8.1 \pm 0.6 \mathrm{fF} / \mathrm{s}\left(n=13\right.$ cells) and transient fusion events in the cell-attached recording $\left(\boldsymbol{a}_{\mathbf{3}}\right)$. A stimulation protocol $(10 \times$ $50 \mathrm{~ms}$ ) was applied to the cell $1 \mathrm{~min}$ after establishing the whole-cell configuration and every 5 min thereafter to track the effect of $\left[C_{a}\right]_{i}$ on RE kinetics. $\boldsymbol{B}$, A concentration of $102 \mu \mathrm{m}$ free $\left[C_{a}\right]_{i}$ triggered a continuous increase in the whole-cell $\boldsymbol{C}_{\mathrm{m}}\left(\boldsymbol{b}_{\boldsymbol{1}}\right)$ at a rate of $13 \pm 0.7 \mathrm{fF} / \mathrm{s}$ ( $n=11$ cells) and evoked both transient fusion and full fusion events in cell-attached traces $\left(\boldsymbol{b}_{3}\right)$. RE is still intact 1 min after getting into the whole-cell recording but compromised at $6 \mathrm{~min}\left(\boldsymbol{b}_{2}\right)$. $\boldsymbol{C}$, A concentration of $210 \mu \mathrm{m}$ free $[\boldsymbol{C a}]_{\mathrm{i}}$ triggered a continuous increase in the whole-cell $C_{m}\left(\boldsymbol{c}_{1}\right)$ at a higher rate of $23.5 \pm 2 \mathrm{fF} / \mathrm{s}(n=11$ cells) and evoked mostly full fusion events in the cell-attached recording $\left(\boldsymbol{c}_{3}\right)$. RE is abolished under these conditions at 1 and $6 \mathrm{~min}\left(\boldsymbol{c}_{2}\right)$. Note that RE is compromised by the second stimulation at $\sim 102 \mu \mathrm{M}\left[\mathrm{Ca}_{\mathrm{i}}\left(\boldsymbol{a}_{2}\right)\right.$ and blocked by the following third or fourth stimulations (data not shown).
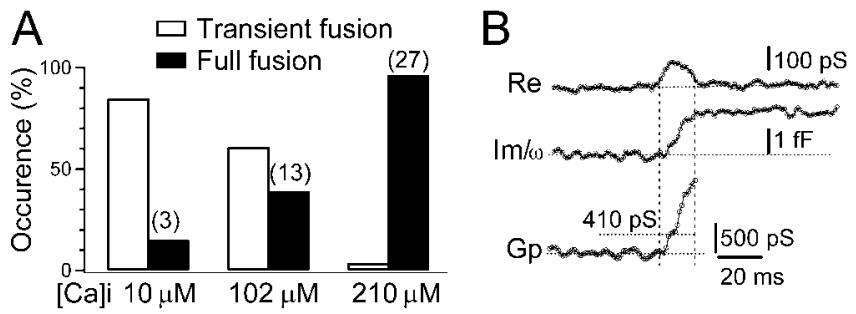

Figure 4. High $[\mathrm{Ca}]_{i}$ shifts the mode of secretion to full fusion. $A$, Different levels of free $\mathrm{Ca}^{2+}$ concentrations were fixed with different $\mathrm{Ca}^{2+}$ buffers (see Materials and Methods) and introduced into the cell through the whole-cell pipette. The occurrence probability of secretory events showing a shift toward full fusion at the expense of transient fusion events at a higher level of $[\mathrm{Ca}]_{\mathrm{i}}$ is shown. The numbers in parentheses are the number of full fusion events in each condition. $\boldsymbol{B}$, Analysis of a full fusion event shown at an expanded time. $C_{\mathrm{v}}=1 \mathrm{~m} / \omega$ and the conductance of the fusion pore is calculated from the imaginary trace $(\mathrm{Im})$ alone, $G_{\mathrm{p}}=\mathrm{Im} /(\mathrm{Im} /$ $(\operatorname{Im}-1))^{\wedge} 1 / 2$ (see Materials and Methods). The $G_{p}$ was calculated only when the fusion pore stabilized for a few milliseconds $(410 \mathrm{pS})$ before it reached high values $(\sim 1 \mathrm{nS})$. The expansion of the fusion pore is expected to be accompanied by a transient increase in the real trace (Re).

itance. At $\sim 10 \mu \mathrm{M}[\mathrm{Ca}]_{\mathrm{i}}$, while whole-cell membrane capacitance $\left(C_{\mathrm{m}}\right)$ increased continuously (Fig. $\left.3 A a_{1}\right)$ at a rate of $8.1 \pm 0.6 \mathrm{fF} / \mathrm{s}$ ( $n=13$ cells), unitary fusion events in the limited region under the cell-attached patch (Fig. $3 \mathrm{Aa}_{3}$ ) were predominantly transient fusion events. When the free $[\mathrm{Ca}]_{\mathrm{i}}$ was increased to $102 \mu \mathrm{M}$ (Fig. $3 B)$, whole-cell $C_{\mathrm{m}}$ increased at a higher rate of $13 \pm 7 \mathrm{fF} / \mathrm{s}(n=$ 11 cells). Under these conditions, both transient and full fusion events were seen in the cell-attached patch recordings, and sometimes both types of events were recorded in the same patch (Fig. $3 \mathrm{Bb}_{3}$ ). Raising $[\mathrm{Ca}]_{\mathrm{i}}$ to $210 \mu \mathrm{m}$ led to a larger $C_{\mathrm{m}}$ rate increase in the whole-cell mode to $23.5 \pm 2 \mathrm{fF} / \mathrm{s}$ ( $n=10$ cells). Here, predominantly full fusion events were detected in the cell-attached patch (Fig. $3 C c_{3}$ ). These results suggest that prevailing $[\mathrm{Ca}]_{\mathrm{i}}$ controls the transition between transient and full fusion.

One possibility is that the principal effect of $[\mathrm{Ca}]_{\mathrm{i}}$ is on fusion pore closure, which in turn might be related to the mechanism of endocytosis. Indeed, during these experiments, it was evident that increasing $[\mathrm{Ca}]_{\mathrm{i}}$ led to significant changes in the kinetics of $\mathrm{RE}$ as detected in whole-cell capacitance recording. Our standard protocol that triggers exocytosis coupled to RE involves short trains of stimuli $(10 \times 50 \mathrm{~ms})$ and in calf AC cells can be reproducibly evoked at $1 \mathrm{~min}$ after establishing whole-cell configuration and every 5 min thereafter (Artalejo et al., 1995, 1996). Indeed, RE is readily apparent and quite reproducible at $\sim 10 \mu \mathrm{M}[\mathrm{Ca}]_{\mathrm{i}}$ but is already compromised by the second stimulation at $\sim 102 \mu \mathrm{M}$ $[\mathrm{Ca}]_{\mathrm{i}}$ and absent altogether at $\sim 210 \mu \mathrm{M}$ [Ca $]_{\mathrm{i}}$ (Fig. 3, compare insets in $a_{2}, b_{2}$, and $c_{2}$ ). Analysis of transient fusion events show that increasing the $[\mathrm{Ca}]_{\mathrm{i}}$ from $10 \mu \mathrm{M}$ $(n=17)$ to $102 \mu \mathrm{M}(n=20)$ does not significantly affect the $C_{\mathrm{v}}(2.17 \pm 0.19$ vs $2.08 \pm 0.09 \mathrm{fF})$ or $G_{\mathrm{p}}(250 \pm 17$ vs $246 \pm$ $18 \mathrm{pS}$ ). However, the mean duration was significantly reduced from $227 \pm 60 \mathrm{~ms}$ (range, 26-780 ms) to $62 \pm 13 \mathrm{~ms}$ (range, 21-230 ms). Given that transient events were virtually absent at $210 \mu \mathrm{M}$ (Fig. 4A) and this pattern paralleled the disappearance of RE as a function of $[\mathrm{Ca}]_{i}$, it immediately raised the question of whether RE is mechanistically associated with transient fusion and that when RE is abrogated full fusion becomes the norm. To answer this question, we used two stimulation protocols that selectively and reproducibly trigger RE or SE.

\section{Kiss-and-run is linked to RE, whereas full fusion is linked to SE}

Previously, we showed that brief $(10 \times 50 \mathrm{~ms})$ and sustained $(29 \times 75 \mathrm{~ms})$ physiological stimulations (square voltage depolarization) trigger two modes of endocytosis dubbed RE and SE, respectively (Artalejo et al., 2002). We also found that replacement of extracellular $\mathrm{Ca}^{2+}$ with $\mathrm{Ba}^{2+}$ or $\mathrm{Sr}^{2+}$ did not affect the extent of secretion or SE significantly but inhibited RE completely (Aratlejo et al., 1995, 1996, 2002). Both of these paradigms were used to investigate the connection between $\mathrm{RE}$ and transient fusion events. Control stimulation with $10 \times 50 \mathrm{~ms}$ pulses again showed reproducible RE in the whole-cell mode (Fig. 5A $a_{1}$ ) and only transient fusion events in the cell-attached patch (Fig. $5 A a_{2}$ ). From a total of 25 transient fusion events gathered from 12 cells, the $C_{\mathrm{v}}$ was $(1.9 \pm 0.1 \mathrm{fF})$, the $G_{\mathrm{p}}$ was $135 \pm 9 \mathrm{pS}$, and the event duration was $70 \pm 8 \mathrm{~ms}$. Interestingly, these transient events have a similar duration as in the two previous conditions, raising $[\mathrm{Ca}]_{\mathrm{i}}$ to $102 \mu \mathrm{M}$ or increasing the frequency of AP stimulation to $7 \mathrm{~Hz}$. All three conditions speed up the closure of the fusion pore to a similar magnitude $(\sim 70 \mathrm{~ms})$. By analogy to the release of catecholamines from DCVs, the mean duration of the amperometric spikes (rising phase plus falling phase) evoked at $7 \mathrm{~Hz}$ APs was 63 ms (Table 1) (Elhamdani et al., 2001).

In contrast, when $\mathrm{Sr}^{2+}$ replaced bath $\mathrm{Ca}^{2+}$, the $10 \times 50 \mathrm{~ms}$ pulse train resulted in only exocytosis with RE being completely blocked (Fig. 5Bb $b_{1}$ ) (cf. Artalejo et al., 1995, 1996). At the same time in the cell-attached patch, only full fusion events were recorded (Fig. $5 \mathrm{Bb}_{2}$ ). The blockade of RE does not affect fusing vesicle size $\left(C_{\mathrm{v}}=1.85 \pm 0.13 ; n=23\right.$ events from nine cells). 
However, the conductance of the fusion pore stabilizes at $415 \pm 40 \mathrm{pS}$ for a few milliseconds before full expansion. Furthermore, when more sustained stimulation was used $(29 \times 75 \mathrm{~ms}$ pulses $)$ in the presence of $\mathrm{Ca}^{2+}$ as charge carrier, the robust $C_{\mathrm{m}}$ increase was followed by a slow decrease in $C_{\mathrm{m}}(\mathrm{SE})$ that takes $\sim 11 \mathrm{~min}$ to return to the baseline value (Fig. $5 C c_{1}$ ) (see also Artalejo et al., 2002). Note that RE does not take place as shown in the wholecell recording, whereas in the cell-attached patch, only full fusion events were apparent (Fig. $5 C c_{2}$ ). Again, the blockade of RE does not affect the vesicle size $\left(C_{\mathrm{v}}=1.8 \pm\right.$ $0.1 \mathrm{fF} ; n=34$ gathered from 14 cells), and in 14 of 34 events, which occurred between stimulations, the $G_{\mathrm{p}}$ stabilizes at $486 \pm 47 \mathrm{pS}$ for a few milliseconds before full fusion. All full fusion events recorded in this condition were evoked between the 20th and 29th stimulation pulses. These results strongly suggest that, at moderate physiological stimulations, RE is intimately coupled to the kiss-and-run type of secretion, whereas full fusion events are followed by SE at more sustained stimulations.

\section{Discussion}

Use of the double patch-clamp approach described in this study has allowed us to determine the kinetics of different modes of secretion under precisely controlled conditions in calf AC cells. Although the success rate of the procedure is quite low $(5-12 \%$ of cells patched), necessitating the testing of large numbers of cells $(>1300$ cells were patched, 128 cells were used in the present study), the advantages conferred by this configuration are substantial. The major conclusions we draw are as follows: (1) transient fusion (kiss-and-run) is the major mechanism of vesicle exocytosis under moderate stimulation conditions; (2) sustained stimulation favors the incidence of full fusion events at the expense of transient events; (3) stimulation frequency controls the open time and the conductance of the fusion pore; (4) high $\left[\mathrm{Ca}^{2+}\right]_{\mathrm{i}}$ favors full fusion, not kiss-and-run; and (5) RE is associated with kiss-and-run events (when RE is abrogated, full fusion takes place and vesicles are recovered by SE), a process that we previously showed is similar to clathrin-coated vesicle endocytosis.

Although transient fusion has recently become more accepted as an alternative mode of secretion to the traditional full fusion model, the lack of direct measurement of fusion pore kinetics under physiological conditions has hindered an evaluation of the prevalence of this mechanism. For example, patch-amperometry studies in rat chromaffin cells claimed that only nonphysiological maneuvers, such as raising external [Ca] to very high levels (90 $\mathrm{mM}$ ), promoted the incidence of kiss-and-run events, suggesting that it may be a minor player under normal physiological circumstances (Alés et al., 1999). A major difference between the present study and the study of Alés et al. (1999) is that the latter results were based solely on spontaneous release, whereas our data reflect release characteristics of cells stimulated in a physiological manner. Thus, although differences between the two sets of observations may be partly attributable to species considerations,
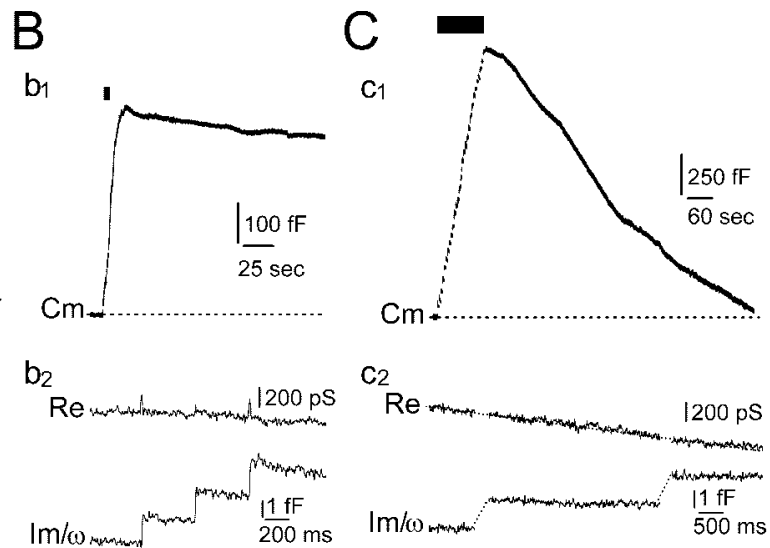

Figure 5. Switch from kiss-and-run to full fusion by blocking RE. $A$, A stimulation protocol $(10 \times 50 \mathrm{~ms})$ triggers an increase in exprane capacitance $\left(C_{m}\right)$, exocytosis, coupled to $\operatorname{RE}\left(\boldsymbol{a}_{\boldsymbol{\gamma}}\right)$. In the mean time, one kiss-and-run event of $1.8 \mathrm{fF}$ was seen in the is in favor of exocytosis during stimulations and in favor of endocytosis at the end of stimulation. $\boldsymbol{B}$. When bath $\boldsymbol{C a}^{2+}$ was substituted for $\mathrm{Sr}^{2+}$ and the cell-attached pipette $\mathrm{Ca}^{2+}$ was substituted for $\mathrm{Sr}^{2+}$, the whole-cell $C_{\mathrm{m}}$ evoked by $10 \times 50$ ms pulses of capacitance recording during the pulses.

our ability to fully control stimulation and $[\mathrm{Ca}]_{\mathrm{i}}$ parameters lends credence to our conclusions. Indeed, calf AC cells manifest insignificant spontaneous release, as monitored at the level of a single secretory event in the cell-attached mode (present data) or as found in amperometric recordings (Elhamdani et al., 1998, 1999, 2001). A similar controversy between the relative importance of transient and full fusion mechanisms has emerged in the synaptic literature. On the one hand, cell-attached capacitance experiments in nonstimulated posterior pituitary nerve terminals suggested that transient fusion represented only $5 \%$ of the total number of fusion events under spontaneous release conditions. However, 55\% of the patches tested in that study did not show any further activity after depolarization with high $\mathrm{KCl}$, suggesting that initial $[\mathrm{Ca}]_{\mathrm{i}}$ levels evoking release were already high (Klyachko and Jackson, 2002). Similarly, vesicle recycling in synaptopHluorin transgenic mice studies claimed that fast recycling in hippocampal neurons is rare based only on one sustained stimulation protocol, APs at $20 \mathrm{~Hz}$ ( $\mathrm{Li}$ et al., 2005). In contrast, recent dye-release experiments performed under mild stimulation conditions (low probability of release) in hippocampal neurons showed that transient fusion may comprise $70-85 \%$ of all events at this excitatory synapse (Richards et al., 2005) (see also Aravanis et al., 2003; Gandhi and Stevens, 2003). Similarly in AC cells, a combination of amperometry and imaging of the uptake of different fluorescent molecules of different sizes, evoked by APs at 0.5 and $15 \mathrm{~Hz}$, was used to probe the size of the vesicle fusion pore (Fulop et al., 2005). Fulop et al. (2005) showed the existence of mainly the kiss-and-run type of secretion at $0.5 \mathrm{~Hz}$ and full fusion at $15 \mathrm{~Hz}$.

We suggest that many studies showing a low incidence of the transient fusion mode of secretion rely mostly on spontaneous release or sustained stimulation (e.g., bath application of high $\mathrm{KCl}$ ) and do not accurately represent normal stimulation conditions.

Another important conclusion that we demonstrate here is a direct connection between RE and kiss-and-run events. Although 
we hypothesized that this was likely true based on circumstantial considerations in our previous work (Elhamdani et al., 2001; for review, see Artalejo et al., 1998), the direct correlation between loss of RE and transient fusion events in cells stimulated with $\mathrm{Sr}^{2+}$ as charge carrier or sustained stimulations indicates that this form of endocytosis is normally part of the kiss-and-run mechanism.

The present data prompts us to elaborate a model of transient and full fusion of DCVs evoked by physiological stimulation in calf AC cells (supplemental Fig. 1, available at www.jneurosci.org as supplemental material). Previous studies have shown the existence of a pool of DCVs in AC cells that are already docked and primed and fuse with the plasma membrane after an elevation in $[\mathrm{Ca}]_{\mathrm{i}}$. However, it is becoming clear that the mode and pattern of $\mathrm{Ca}^{2+}$ elevation also plays a role in determining the type of fusion that takes place. In our model, different $[\mathrm{Ca}]_{\mathrm{i}}$ governed by different patterns of stimulation give rise to at least three modes of fusion and vesicle recycling. (1) At low stimulation frequency (low $\left.[\mathrm{Ca}]_{\mathrm{i}}\right)$, vesicles fuse with plasma membrane for a longer duration ( $\sim 200 \mathrm{~ms}$ ) through a narrow fusion pore. This is in line with our previous amperometry data showing that the amperometric spikes evoked at low frequency or low external [Ca] are smaller in amplitude but wider than those evoked at higher frequencies (Elhamdani et al., 2001). Interestingly, these spikes were not affected by antagonism of dynamin function, suggesting that the closure of the fusion pore in "mode 1" may simply be a reversal of the fusion reaction, possibly similar to that found in synaptic terminals (Ceccarelli et al., 1973; Stevens and Williams, 2000), AC cells (Graham et al., 2002), and PC12 cells (Holroyd et al., 2002; for review, see Südhof, 2004). (2) At moderate stimulation (medium $[\mathrm{Ca}]_{\mathrm{i}}$ ), DCVs fuse transiently but for a shorter duration ( $\sim 70 \mathrm{~ms}$ ) and higher pore conductance. Because RE involves $\mathrm{Ca}^{2+}$ and dynamin-1, it is most likely that this level of $[\mathrm{Ca}]_{\mathrm{i}}$ corresponds to a specific threshold, which could trigger the formation of a dynamin-1 ring around the neck of the retracting vesicle, facilitating the closure of the fusion pore and initiating fission. This hypothesis is also supported by the fact that when RE is abrogated with sustained stimulations or high free $[\mathrm{Ca}]_{i}$, only full fusion events were seen at the expense of kiss-and-run events. (3) At sustained stimulation (high $[\mathrm{Ca}]_{\mathrm{i}}$ ), dynamin-1-dependent $\mathrm{RE}$ is blocked. Therefore, the absence of dynamin-1 rings around the neck of the vesicle might allow the fusion pore, which is already at high conductance in presence of high $\mathrm{Ca}^{2+}$, to expand until full collapse of the vesicle with the plasma membrane. These vesicles will be retrieved by the clathrin- and dynamin-2-dependent SE and recycled through the endosomal compartment.

What is the mechanism by which $[\mathrm{Ca}]_{\mathrm{i}}$ regulates the switch between RE and SE, or between transient and full fusion? Although this is still unknown, a prime candidate might be the $\mathrm{Ca}^{2+}$-sensitive phosphatase calcineurin. We suggested previously (Artalejo et al., 2002) that calcineurin-dependent dephosphorylation of dynamin-1 might reduce its ability to mediate RE (key factors here may be the dependence of dynamin-1 GTPase activity on phosphorylation state and/or the ability of dynamin-1 to reassociate with its anchoring protein amphiphysin when dephosphorylated). Thus, high $\mathrm{Ca}^{2+}$ might promote rapid dephosphorylation of dynamin-1 and compromise RE, thus biasing the system toward other means of endocytosis. Indeed, our previous studies using calcineurin antagonists showed that blocking this enzyme in calf AC cells caused an acceleration of RE as reflected in whole-cell membrane capacitance recordings (Artalejo et al., 1996). Similarly, blockade of calcineurin function accelerates ves- icle recycling in nerve terminals of Drosophila larvae (Kuromi et al., 1997, Kuromi and Kidokoro, 1999).

We believe the present results might be relevant to synaptic transmission. Until recently, the bulk of evidence relating to the plasticity of neurotransmission concerned the postsynaptic and synaptic cleft compartments. Now that attention has shifted to the presynaptic arena (Krupa and Liu, 2004), it is apparent that regulation of the fusion pore may be a key element in the regulation of quantal size (Elhamdani et al., 2001; Aravanis et al., 2003; Pawlu et al., 2004; Staal et al., 2004) and synaptic strength (Choi et al., 2000; Renger et al., 2001; Zakharenko et al., 2002). In light of our present data, we suggest that the opening duration and the conductance of the fusion pore are governed by the pattern of stimulation and thereby dictate the rate and amount of transmitter released. As shown in supplemental Figure 1 (available at www.jneurosci.org as supplemental material), mode 1 is mediated by a smaller pore and longer open time. Therefore, a small amount of transmitter will be released for a longer duration. At low activity, this mode of release is important to maintain a low basal level of release with few vesicles, especially if the release ready pool contains a small number of vesicles. In synaptic terminals, this mode of release has been suggested to play an important role in maintaining the synapse silent by desensitization of the receptors at the postsynaptic level (Choi et al., 2000). During mode 2 , secretion is very efficient, and the same vesicle is retrieved intact and could be reused after refilling with transmitter from the cytoplasm. Indeed fluorescent "timer" proteins show that the youngest vesicles in the release ready pool are released first by nicotinic stimulation of AC cells (Duncan et al., 2003). In synaptic terminals, a brief release of glutamate at a high rate could turn a glutamatergic silent synapse into an active one (Choi et al., 2000). Under sustained stimulation (mode 3), vesicles will dump their entire content into the bloodstream or the synaptic cleft and the fusion pore expands irreversibly promoting full vesicle fusion with the surface membrane. As shown in many classical studies on synaptic vesicle recycling under tetanic conditions, vesicle retrieval is via a coated vesicle route with an obligate endosomal intermediate required to regenerate the synaptic vesicle population (Heuser and Reese, 1973). We have shown that this pathway coexists with other mechanistically distinct routes for vesicle retrieval that may play key roles in regulating transmitter release under physiological conditions.

\section{References}

Alés E, Tabares L, Poyato JM, Valero V, Lindau M, Alvarez de Toledo G (1999) High calcium concentrations shift the mode of exocytosis to the kiss-and-run mechanism. Nat Cell Biol 1:40-44.

Alvarez de Toledo G, Fernandez-Chacon R, Fernandez JM (1993) Release of secretory products during transient vesicle fusion. Nature 363:554-558.

Aravanis AM, Payle JL, Harata NC, Tsien RW (2003) Imaging single synaptic vesicles undergoing repeated fusion events: kissing, running, and kissing again. Neuropharmacology 45:797-813.

Artalejo CR, Henley JR, McNiven MA, Palfrey HC (1995) Rapid endocytosis coupled to exocytosis in adrenal chromaffin cells involves $\mathrm{Ca}^{2+}, \mathrm{GTP}$ and dynamin but not clathrin. Proc Natl Acad Sci USA 92:8328-8332.

Artalejo CR, Elhamdani A, Palfrey HC (1996) Calmodulin is the divalent cation receptor for rapid endocytosis, but not exocytosis, in adrenal chromaffin cells. Neuron 16:195-205.

Artalejo CR, Elhamdani A, Palfrey HC (1998) Secretion: dense-core vesicles can kiss-and-run too! Curr Biol 8:R62-R65.

Artalejo CR, Elhamdani A, Palfrey HC (2002) Sustained stimulation shifts the mechanism of endocytosis from dynamin-1-dependent rapid endocytosis to clathrin- and dynamin-2-mediated slow endocytosis in chromaffin cells. Proc Natl Acad Sci USA 99:6358-6363.

Ceccarelli B, Hurlbut WP, Mauro A (1973) Turnover of transmitter and 
synaptic vesicles at the frog neuromuscular junction. J Cell Biol 57:499-524.

Choi S, Klingauf J, Tsien RW (2000) Postfusional regulation of cleft glutamate concentration during LTP at "silent synapses." Nat Neurosci 3:330-336.

Debus K, Lindau M (2000) Resolution of patch capacitance recordings and fusion pore conductances in small vesicles. Biophys J 78:2983-2997.

De Camilli P, Slepnev VI, Shupliakov O, Brodin L (2000) Synaptic vesicle endocytosis. In: Synapses (Cowan WM, Südhof TC, Stevens CF, eds), pp 217-274. Baltimore: Johns Hopkins UP.

Del Castillo J, Katz B (1954) Quantal components of the end-plate potential. J Physiol (Lond) 124:560-573.

Dernick G, Alvarez de Toledo G, Lindau M (2003) Exocytosis of single chromaffin granules in cell-free inside-out membrane patches. Nat Cell Biol $5: 358-362$.

Dickman DK, Horne JA, Meinertzhagen IA, Schwarz TL (2005) A slowed classical pathway rather than kiss-and-run mediates endocytosis at synapses lacking synaptojanin and endophilin. Cell 123:521-533.

Duncan RR, Greaves J, Wiegand UK, Matskevich L, Bodammer G, Apps DK, Shipston MJ, Chow RH (2003) Functional and spatial segregation of secretory vesicle pools according to vesicle age. Nature 422:176-180.

Elhamdani A, Zhou Z, Artalejo CR (1998) Timing of dense-core vesicle exocytosis depends on the facilitation L-type Ca channel in adrenal chromaffin cells. J Neurosci 18:6230-6240.

Elhamdani A, Martin TFJ, Kowalchyk JA, Artalejo CR (1999) CAPS (Cadependent activator protein for secretion) is critical for the fusion of dense-core vesicles with the membrane in calf adrenal chromaffin cells. J Neurosci 19:7375-7383.

Elhamdani A, Palfrey HC, Artalejo CR (2001) Quantal size is dependent on stimulation frequency and calcium entry in calf chromaffin cells. Neuron 31:819-830.

Fernandez JM, Neher E, Gomperts BD (1984) Capacitance measurements reveal stepwise fusion events in degranulating mast cells. Nature 312:453-455.

Fulop T, Radabaugh S, Smith C (2005) Activity-dependent differential transmitter release in mouse adrenal chromaffin cells. J Neurosci 25:7324-7332.

Gandhi SP, Stevens CF (2003) Three modes of synaptic vesicular recycling revealed by single-vesicle imaging. Nature 423:607-613.

Graham ME, O'Callaghan DW, McMahon HT, Burgoyne RD (2002) Dynamin-dependent and dynamin-independent processes contribute to the regulation of single vesicle release kinetics and quantal size. Proc Natl Acad Sci USA 99:7124-7129.

Han X, Wang C-T, Bai J, Chapman ER, Jackson MB (2004) Transmembrane segments of syntaxin line the fusion pore of $\mathrm{Ca}^{2+}$-triggered exocytosis. Science 304:289-292.

Henkel AW, Meiri H, Horstmann H, Lindau M, Almers W (2000) Rhythmic opening and closing of vesicles during constitutive exo- and endocytosis in chromaffin cells. EMBO J 19:84-93.

Heuser JE, Reese TS (1973) Evidence for recycling of synaptic vesicle mem- brane during transmitter release at the frog neuromuscular junction. J Cell Biol 133:315-344.

Holroyd P, Lang T, Wenzel D, De Camilli P, Jahn R (2002) Imaging direct, dynamin-dependent recapture of fusing secretory granules on plasma membrane lawns from PC12 cells. Proc Natl Acad Sci USA 24:16806-16811.

Klyachko VA, Jackson MB (2002) Capacitance steps and fusion pores of small and large-dense-core vesicles in nerve terminals. Nature 418:89-92.

Krupa B, Liu G (2004) Does the fusion pore contribute to synaptic plasticity? Trends Neurosci 27:62-66.

Kuromi H, Kidokoro Y (1999) The optically determined size of exo/endo cycling vesicle pool correlates with the quantal content at the neuromuscular junction of Drosophila larvae. J Neurosci 19:1557-1565.

Kuromi H, Yoshihara M, Kidokoro Y (1997) An inhibitory role of calcineurin in endocytosis of synaptic vesicles at larvae. Neurosci Res 27:101-113.

Li Z, Burrone J, Tyler WJ, Hartman KN, Albeanu DF, Murthy VN (2005) Synaptic vesicle recycling studied in transgenic mice expressing synaptopHluorin. Proc Natl Acad Sci USA 102:6131-6136.

Murthy VN, De Camilli P (2003) Cell biology of the presynaptic terminal. Annu Rev Neurosci 26:701-728.

Neher E, Marty A (1982) Discrete changes of cell membrane capacitance observed under conditions of enhanced secretion in bovine adrenal chromaffin cells. Proc Natl Acad Sci USA 79:6712-6716.

Ornberg RL, Furuya S, Goping G, Kuijpers GA (1995) Granule swelling in stimulated bovine adrenal chromaffin cells: regulation by internal granule pH. Cell Tissue Res 279:85-92.

Palfrey HC, Artalejo CR (1998) Vesicle recycling revisited: rapid endocytosis may be the first step. Neuroscience 83:969-989.

Pawlu C, DiAntonio A, Heckmann M (2004) Postfusional control of quantal current shape. Neuron 42:607-618.

Renger JJ, Egles C, Liu G (2001) A developmental switch in neurotransmitter flux enhances synaptic efficacy by affecting AMPA receptor activation. Neuron 29:469-484.

Richards DA, Bai J, Chapman ER (2005) Two modes of exocytosis at hippocampal synapses revealed by rate of FM1-43 efflux from individual vesicles. J Cell Biol 168:929-939.

Staal RG, Mosharov EV, Sulzer D (2004) Dopamine neurons release transmitter via a flickering fusion pore. Nat Neurosci 7:341-346.

Stevens CF, Williams JH (2000) "Kiss and run" exocytosis at hippocampal synapses. Proc Natl Acad Sci USA 97:12828-12833.

Südhof TC (2004) The synaptic vesicle cycle. Annu Rev Neurosci 27:509-547.

Taraska JW, Perrais D, Ohara-Imaizumi M, Nagamatsu S, Almers W (2003) Secretory granules are recaptured largely intact after stimulated exocytosis in cultured endocrine cells. Proc Natl Acad Sci USA 100 :2070-2075.

Zakharenko SS, Zablow L, Siegelbaum SA (2002) Altered presynaptic vesicle release and cycling during mGluR-dependent LTD. Neuron 35:10991110. 